\title{
Reversible electrokinetic adsorption barriers for the removal of atrazine and oxyfluorfen from spiked soils
}

\author{
E. Vieira dos $\operatorname{Santos}^{1}$, C. Sáez ${ }^{2}$, P. Cañizares ${ }^{2}$, C.A. Martínez-Huitle ${ }^{3}$, M.A. Rodrigo ${ }^{2, *}$ \\ ${ }^{1}$ School of Science and Technology, Federal University of Rio Grande do Norte, Campus \\ Universitario, 59078-970 Natal, Brazil
}

${ }^{2}$ Department of Chemical Engineering, Enrique Costa Building, Campus Universitario s/n, 13071 Ciudad Real, Spain

${ }^{3}$ Institute of Chemistry, Federal University of Rio Grande do Norte, Campus Universitario, 59078-970 Natal, Brazil

\begin{abstract}
This study demonstrates the application of reversible electrokinetic adsorption barrier (REKAB) technology to soils spiked with low-solubility pollutants. A permeable reactive barrier (PRB) of granular activated carbon (GAC) was placed between the anode and cathode of an electrokinetic (EK) soil remediation bench-scale setup with the aim of enhancing the removal of two low-solubility herbicides (atrazine and oxyfluorfen) using a surfactant solution (sodium dodecyl sulfate) as the flushing fluid. This innovative study focused on evaluating the interaction between the EK system and the GAC-PRB, attempting to obtain insights into the primary mechanisms involved. The obtained results highlighted the successful treatment of atrazine and oxyfluorfen in contaminated soils. The results obtained from the tests after 15 days of treatment were compared with those obtained using the more conventional electrokinetic soil flushing (EKSF) technology, and very important differences were observed. Although both technologies are efficient for removing the herbicides from soils, REKAB outperforms EKSF. After the 15-day
\end{abstract}


treatment tests, only approximately $10 \%$ of atrazine and oxyfluorfen remained in the soil, and adsorption onto the GAC bed was an important removal mechanism (15-17\% of herbicide retained). The evaporation loses in REKAB were lower than those obtained in EKSF (45-50\% compared to $60-65 \%)$.

\section{Keywords}

Electrokinetic; REKAB; soil remediation; permeable reactive barrier; atrazine; oxyfluorfen

\section{Highlights}

- REKAB technology efficiently removes atrazine and oxyfluorfen from soil.

- Synergistic interaction between electrokinetics and GAC permeable reactive barrier.

- Significant carbon bed-adsorption mechanism for atrazine and oxyfluorfen

- Volatilization of herbicides is prevented in the REKAB technology

- Reversible changes in the polarity control avoid extreme $\mathrm{pH}$ values.

*Author to whom all correspondence should be addressed: Manuel.Rodrigo@uclm.es 


\section{Introduction}

Over the past decades, concerns about the application of herbicides have been increasing, particularly about their effects on the environment (Rodrigo et al., 2014). Currently, the use of herbicides is very common in most agricultural regions of the world, providing great advantages related to improved crop production. Consequently, since the mid1940s, the industrial production of organic herbicides has continuously increased, and even now it continues to progressively increase. The negative environmental impact of herbicides is related to water and soil contamination, which has received a considerable amount of attention from the scientific community (Ribeiro et al., 2005; Grube et al., 2007; Gomes et al., 2012; Eason et al., 2013; Frische et al., 2013; Ryberg and Gilliom, 2015). From an environmental perspective, a very interesting classification of herbicides is related to their solubility. Low-solubility herbicides are typically formulated as emulsions to favour their application. The transport properties of such herbicides when they become pollutants strongly depend on the matrices used in the commercial formulation. Among the low-solubility herbicides, there are two that are of particular interest and are the focus of this manuscript: oxyfluorfen and atrazine. Oxyfluorfen (2chloro-1-(3-ethoxy-4-nitrophenoxy)-4-(trifluoromethyl) benzene) is a diphenyl-ether herbicide that is used for broad spectrum pre- and post-emergent control of various annual broadleaf and grassy weeds (Mantzos et al., 2014). This herbicide has low water solubility $\left(0.1 \mathrm{mg} / \mathrm{dm}^{-3}\right.$ at $\left.22^{\circ} \mathrm{C}\right)$, low vapour pressure $\left(0.026 \mathrm{mPa}\right.$ at $\left.25^{\circ} \mathrm{C}\right)$, high $\mathrm{Koc}(\log \mathrm{Koc}=$ 3.46-4.13) and high Kow ( $\log$ Kow $=4.86)$. Atrazine (1-chloro-3-ethylamino-5isopropylamino-2,4,6-triazine) is characterized by a low biodegradability, long half-life, low vapour pressure $\left(0.0385 \mathrm{mPa}\right.$ at $\left.25^{\circ} \mathrm{C}\right)$ and low solubility in water $\left(33 \mathrm{mg} \mathrm{dm}^{-3}\right.$ at $22^{\circ} \mathrm{C}$ ) (Malpass et al., 2006; Oturan et al., 2012), and because of its hazardousness, it was 
banned in the European Union, although it remains in use in many other countries around the world.

One of the worst types of events related to the pollution caused by these herbicides is associated with accidental leakage, which may become a major source of diffuse pollution. To prevent serious environmental problems under accidental discharges of these species, it is very important to take rapid actions against accidental discharges of hazardous species using efficient technologies that help to rapidly remediate the soil (Pazos et al., 2010). Electrokinetic (EK) remediation integrated with permeable reactive barriers (PRBs) has been investigated by several authors in recent years (Palmer, 2001; Choi et al., 2007; Chung and Lee, 2007; Weng, 2009; Mena et al., 2015), and this technology appears to be a very promising alternative. This technological approach was implemented primarily because EK also enables the use of PRB in low-permeability soils (Hayes and Marcus, 1997). Thus, when a PRB is coupled with EK remediation, the flow of pollutants through the PRB is not provided by the transport driven by the hydraulic gradient of groundwater; rather, it is driven by the electro-osmotic flow of soil pore fluid, electromigration or electrophoresis (particularly in low-permeability soils) (Ferri et al., 2009; Wan et al., 2010; Li et al., 2011). As the contaminated groundwater passes through the PRB, contaminants may be degraded or sequestered and clean groundwater exits the PRB. The reactive materials commonly considered include reductions using elemental metals, adsorption with porous high-surface-area materials, ion exchange with resinbased materials, biological degradation, limestone, çhydroxyapatite, active carbon and zeolites (Hayes and Marcus, 1997). The use of inexpensive reactive materials as permeable barriers, such as granular activated carbon (GAC), should contribute towards improving the cost effectiveness of the combined treatment and increasing environmental sustainability (Huang et al., 2015). Consequently, PRBs have been extensively proposed 
for the remediation of inorganic and organic pollutants in groundwater (Scherer et al., 2000; Wan et al., 2010; Li et al., 2011; Garcia et al., 2015).

Regarding the use of EK-PRB with herbicides, a first experience in the application of the combination of EKSF with adsorption barriers was reported for the removal of trichlorophenol (not exactly a herbicide but highly related to these toxic pollutants from a chemical perspective) from spiked soils (Ruiz et al., 2014), where its high efficiency and easy performance were demonstrated. Another interesting experience came from the use of biobarriers in the removal of diesel, where it was concluded that the application of polarity reversal allows for considerably better performance (Mena et al., 2015; Mena et al., 2016a, b). The advantages of reversible changes in polarity were also noted by many other authors (Cameselle and Reddy, 2013). The reversible changes in polarity help to suppress acidification and basification of the contaminated soil in the close vicinity of the electrodes' surfaces and prevents the depletion of ionic species. This fact is of special relevance in combinations of EKSF with biological barriers because non-reversible processes lead to the exhaustion of nutrients in soil.

To date, no studies on the removal of atrazine and oxyfluorfen from soil by EK-PRB coupling have been reported. Consequently, the authors of the present work considered that it would be interesting to investigate the feasibility of coupling EKSF and GAC-PRB to remove atrazine and oxyfluorfen from low-permeability soil using an innovative process called reversible electrokinetic adsorption barrier (REKAB) technology. For the setting of this process, the previous experience of our group, gained in the development of easier technologies such as EK combined with non reversible adsorption permeable barriers and biobarriers has been used. In this context, this work aims to describe the removal of atrazine and oxyfluorfen from clay soils using electrokinetically assisted soil flushing (with sodium dodecyl sulfate (SDS) as the flushing solution) coupled with a PRB 
consisting of beds of GAC and to assess the influence of the electric field on the efficiency of this technology.

\section{Materials and Methods}

\subsection{Chemicals}

Kaolinite, provided by Manuel Riesgo Chemical Products (Madrid, Spain), was used as a model of clay soil (Mena et al., 2011). Atrazine and oxyfluorfen (Sigma-Aldrich), were of analytical grade and used as received. HPLC-grade acetonitrile (Sigma-Aldrich, Spain) was used as the mobile phase in high-performance liquid chromatography (HPLC) analyses. Hexane and ethyl acetate (Sigma-Aldrich, Spain) were used as solvents for the extraction of liquid and solid samples. Granular activated carbon (granule size of 1.25$3.15 \mathrm{~nm}$ ) was purchased from Panreac (Spain). Graphite electrodes $\left(100.0 \mathrm{~cm}^{2}\right)$ provided by Carbosystem (Madrid, Spain) were used as the electrode material.

\subsection{Experimental procedure}

The bench setup used in this work was constructed from transparent methacrylate and divided into seven compartments (Figure 1)(Vieira dos Santos et al., 2016). 


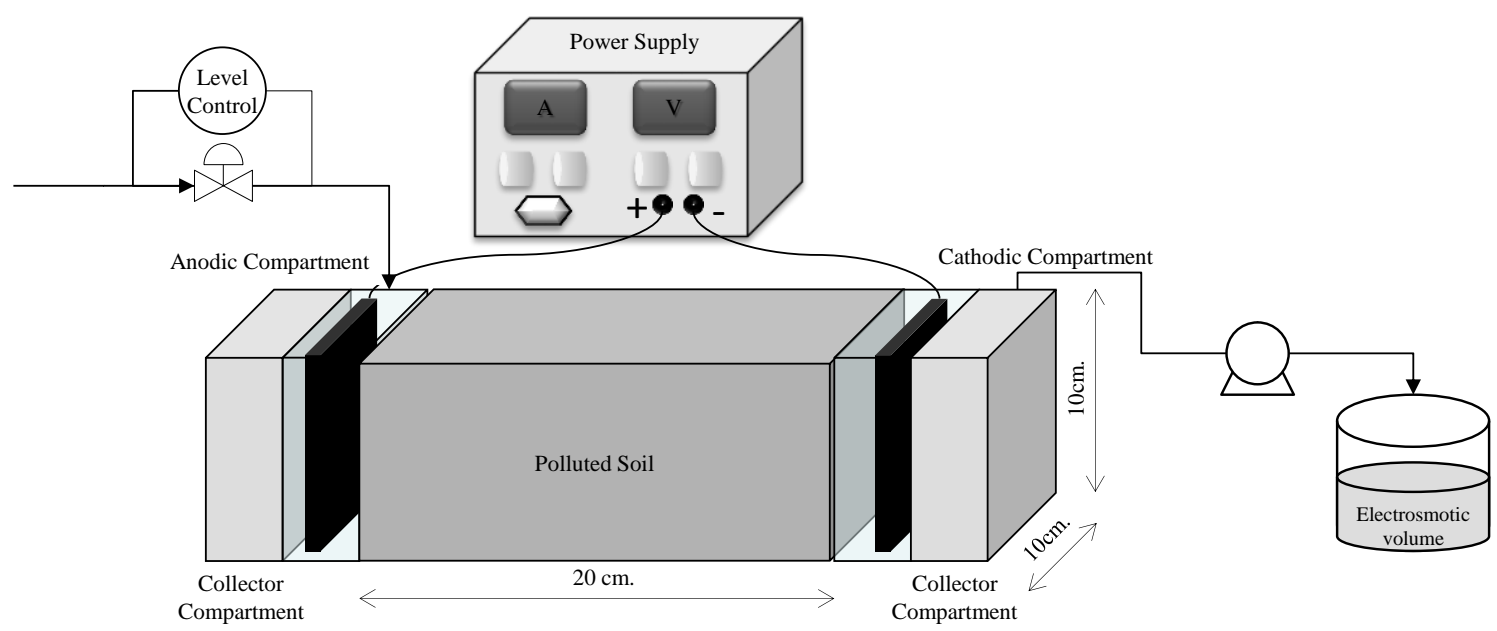

a)

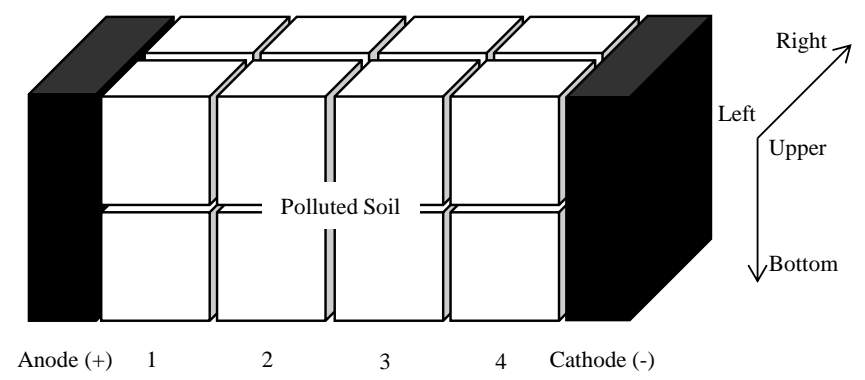

b)

Figure 1. a) Experimental setup used to study the REKAB process and b) Sampling point for post mortem analysis.

The central compartment with a length of $20 \mathrm{~cm}$ was loaded with herbicide-polluted soil and an active carbon PRB, which was manually compacted and separated from the electrode compartments by a $0.5 \mathrm{~mm}$ nylon mesh. One of these compartments contained the anode, and the other contained the cathode. Each electrode compartment was connected to additional compartments to collect the liquid overflowing from the wells that is transported due to the EK processes. The experiments were performed in potentiostatic mode, i.e., setting a voltage of $1.0 \mathrm{~V} \mathrm{~cm}^{-1}$. The duration of the experiments was 15 days, which is long enough to provide a clear overview of the main process occurring in the soil and short enough to avoid the depletion of herbicides (this was intentionally sought to evaluate the removal mechanisms). 
Because the carbon PRB areas were placed in an intermediate section of the installation, far away from the electrodes, it was necessary to use a surfactant to promote the transport of the atrazine and oxyfluorfen. A flushing fluid that consisted of a SDS surfactant solution (1000 $\mathrm{mg} \mathrm{dm}^{-3}$ ) was used as the solubilizing agent. Because SDS is an anionic surfactant, the superficial charge of the atrazine-SDS or oxyfluorfen-SDS micelles is expected to be negative (Santos et al., 2015; dos Santos et al., 2016), and consequently, they are expected to be transported from the cathodic zone towards the anodic compartment, with the atrazine and oxyfluorfen being adsorbed when passing through the carbon PRB. The polarity of the electric field applied between the electrodes was reversed once a day (value selected arbitrarily), and this periodic change will help to explain the zig-zag changes observed in the $\mathrm{pH}$ values of the electrolytes contained in the wells throughout the experiment.

The model soil was spiked with $960 \mathrm{~mL}$ of herbicide aqueous solutions $\left(100 \mathrm{mg} \mathrm{dm}^{-3}\right)$ until an initial pollutant concentration of $30 \mathrm{mg}$ per $\mathrm{kg}$ of soil was obtained. In the case of atrazine and oxyfluorfen solutions, SDS was used as the solubilizing agent (1000 mg $\mathrm{dm}^{-3}$ ). The initial target moisture level of the soil was $30 \%$. The polluted soil was manually compacted in an attempt to avoid the formation of heterogeneities in the soil, which may result in preferential paths for fluid transport. The levels of the anode wells were maintained using a level regulation loop. Water was pumped daily from the cathode well and electroosmotic flux (Jeo) was estimated by equation 1 , where $\mathrm{V}$ is the volume of water recovered $\left(\mathrm{cm}^{3}\right), \mathrm{t}$ is the time (d) and $\mathrm{S}$ is the section of the soil $\left(\mathrm{cm}^{2}\right)$. Evaporation loss was estimated by mass balance.

$$
\mathrm{J}_{\mathrm{eo}}=\frac{\mathrm{dV}}{\mathrm{dt}} \frac{1}{\mathrm{~S}}
$$


Electrical current, temperature, $\mathrm{pH}$, and pollutant concentration in the electrolyte compartments were monitored daily. Moreover, at the end of the experiments, an in-depth sectioned analysis of the complete soil section and of the PRB used were performed (see Figure 1b). This helps to estimate the amount of pesticide transported by electromigration and electroosmosis, and retained in the PRB. The amount of pesticide transferred to atmosphere was estimated by mass balance.

\subsection{Adsorption equilibria}

To better understand the removal of atrazine and oxyfluorfen by REKAB, adsorption equilibrium isotherms $\left(25^{\circ} \mathrm{C}\right)$ were obtained by conducting several batch tests using agitated vessels $(0.25 \mathrm{~L})$ with $0.1 \mathrm{~L}$ solutions of $100 \mathrm{mg} \mathrm{L}^{-1}$ atrazine and oxyfluorfen and increasing amounts ( 2 to $100 \mathrm{mg} \mathrm{L}^{-1}$ ) of activated carbon until equilibrium was reached. A reaction time of $24 \mathrm{~h}$ (as established by preliminary kinetic tests) was used for subsequent equilibrium tests. After the specified time, the samples were filtered through $0.45 \mu \mathrm{m}$ cellulose acetate syringe membrane filters and analysed by HPLC as discussed in Section 2.5. The solution $\mathrm{pH}$ was not adjusted to keep the equilibrium systems simple, limiting the effects of ions from acid or base addition, and because the impact of the solution $\mathrm{pH}$ on the uptake of atrazine or oxyfluorfen was considered to be insignificant.

\subsection{Analytical techniques}

Moisture measurements were performed gravimetrically by drying the soil samples in an oven for $24 \mathrm{~h}$ at $105^{\circ} \mathrm{C}$. To determine the $\mathrm{pH}$ and conductivity of the soil samples, the standard method (E.P.A.-9045C, 1995) for saturated soil was used. The pH measurements were performed using a WTW inoLab pH meter. Conductivity was measured using a GLP 31 conductivity meter (Crisol Instruments, Spain). All the samples (pre- and post- 
mortem) were filtered through $0.45 \mu \mathrm{m}$ nylon filters prior to analysis. The atrazine and oxyfluorfen concentrations in the liquid samples were determined daily using a liquidliquid (L-L) extraction method. The atrazine and oxyfluorfen concentrations were determined by HPLC using an Agilent 1100 (Agilent Technologies, Palo Alto, California, EEUU) equipped with a UV detector and a $150 \times 3.0 \mathrm{~mm}$ Gemini $51 \mathrm{C} 18110^{\mathrm{a}}$ column (Phenomenex, Ref. 00F-4435-YYO), with acetonitrile/water (45:55 V/V) at a flow rate of $0.3 \mathrm{~cm}^{3} \mathrm{~min}^{-1}$ as the mobile phase and at $223 \mathrm{~nm}$ for atrazine and with acetonitrile/water $(70: 30 \mathrm{~V} / \mathrm{V})$ at a flow rate of $0.25 \mathrm{~cm}^{3} \mathrm{~min}^{-1}$ as the mobile phase and at $220 \mathrm{~nm}$ for oxyfluorfen. The total organic carbon (TOC) concentration was monitored using a Multi N/C 3100 Analytik Jena analyser. The soil temperature was monitored using a Digital Soil thermometer.

\section{Results and Discussion}

In this work, to evaluate the performance of the REKAB process, two tests were conducted, one for each model herbicide tested (atrazine and oxyfluorfen). All operating conditions were maintained constant in the two tests.

Part a of Figure 2 presents information about the changes in the applied electric current as a consequence of the application of the REKAB process to both spiked soils. During the 15-day duration of the tests, the current intensity progressively increased $10 \%$, showing values slightly over $4 \mathrm{~mA} \mathrm{~cm}^{-2}$. This increase can be associated with a small increase in the conductivity of the wells and in the moisture of the soil (discussed afterwards), and hence, to the resulting lower ohmic loses. Part b of Figure 2 focuses on the variations in $\mathrm{pH}$ and conductivity obtained in the wells. As in Part a, there are no considerable differences between the two tests (each of them with different herbicides), clearly indicating the robustness of the results obtained in this work. Note that the polarity 
of the electric field applied between the electrodes was reversed once a day (time span for the polarity reversal was arbitrarily selected), and this periodic change helps to explain the zig-zag changes observed in the $\mathrm{pH}$ values of the electrolytes contained in the wells throughout the experiment. Consequently, it also helps to demonstrate that no $\mathrm{pH}$ gradients were formed in the soil between the electrodes (because of the daily neutralization). Note that a buffer solution was not added to the electrolyte during the tests; the only strategy that was applied to regulate the $\mathrm{pH}$ was the daily reversal of the polarity. As shown in this figure, the $\mathrm{pH}$ in the anodic and cathodic wells does not tend to extreme values as is the expected trend in EKSF processes; rather, it tends to more neutral values within the range of 7 to 11 . Typically, a single EK process generates an acidic front in the anodic well and a basic front in the cathodic well as a consequence of (i) the production of protons (during water oxidation) and hydroxyl anions (during water reduction) in the anode and cathode wells, respectively, as shown in equations 2 (anode) and 3 (cathode), and (ii) the transport of $\mathrm{H}^{+}$and $\mathrm{OH}^{-}$ions by the electromigration phenomenon. Hence, polarity reversal contributes to better EK remediation performance by preventing the occurrence of extreme $\mathrm{pH}$ changes in regions of the soil close the electrode wells. This is a positive aspect because according to the literature, (Ribeiro et al., 2005; Wan et al., 2010; Li et al., 2011) controlling the $\mathrm{pH}$ at the anode and cathode appears to result in favourable soil $\mathrm{pH}$ for desorption and electro-osmotic flux

$$
\begin{aligned}
2 \mathrm{H}_{2} \mathrm{O} \longrightarrow \mathrm{O}_{2(\text { gas })}+4 \mathrm{H}^{+}{ }_{(\mathrm{aq})}+4 \mathrm{e}^{-} & \mathrm{E}^{\circ}=-1.229 \mathrm{~V} \\
4 \mathrm{H}_{2} \mathrm{O}+4 \mathrm{e}^{-} \longrightarrow 2 \mathrm{H}_{2 \text { (gas) }}+4 \mathrm{OH}_{(\mathrm{aq})}^{-} & \mathrm{E}^{\circ}=-0.828 \mathrm{~V}
\end{aligned}
$$

Regarding the conductivity, a slight increase in both the anolyte and catholyte was observed during both REKAB tests, indicating that ions are removed from the soil and transported to the wells. This increase in conductivity is primarily due to the electromigration of ions towards the anodic and cathodic wells and due to the production 
of protons and hydroxyl ions during water oxidation and reduction, respectively. As a consequence of the first process, there is a decrease in the conductivity of the soil. The transport of the SDS added to favour the mobility of the herbicides is also expected to have an influence on the changes in the conductivity.

a)

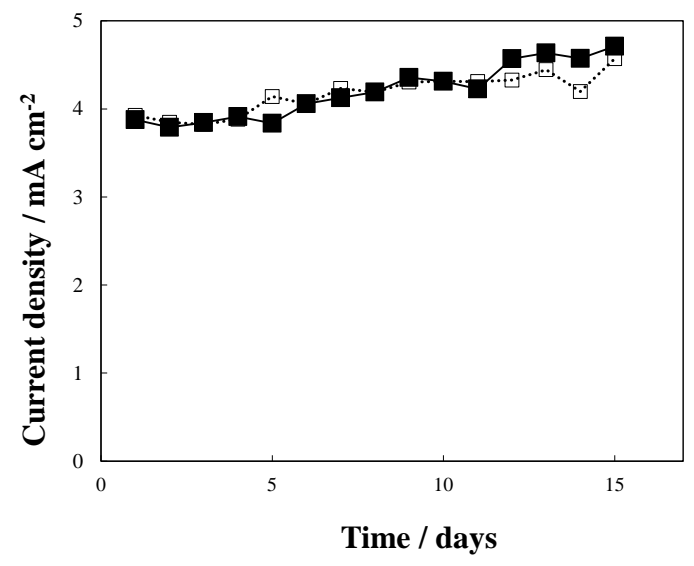

b)

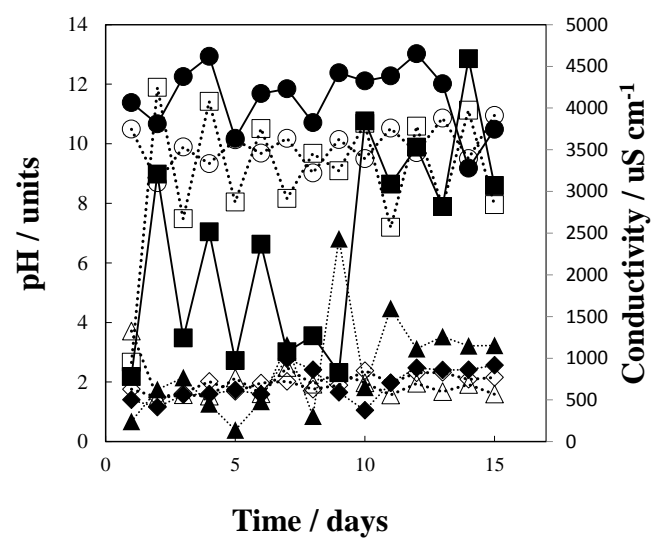

Figure 2. Changes in the main operating parameters during the remediation of the soil by electroremediation powered by a power supply at $20 \mathrm{~V} \mathrm{~cm}^{-1}$ for both pesticides. Atrazine (full symbols) and oxyfluorfen (empty symbols) (a) Current density ( $\mathbf{(}, \square)$. (b) anodic compartment $\mathrm{pH}(\boldsymbol{\square}, \square)$, cathodic compartment $\mathrm{pH}(\bullet, \circ)$, anodic reservoir conductivity $(\diamond, \diamond)$, and cathodic reservoir conductivity $(\boldsymbol{\Delta}, \Delta)$.

Figure 3 presents a 3-D map of the $\mathrm{pH}$ and conductivity distribution at the end of the tests (post-mortem analysis). The first important aspect to note is the very similar behaviours of both tests. Likewise, note that despite the significance of the processes occurring in the electrodes, both parameters are maintained almost constant in the soil and dispersion is very low. 

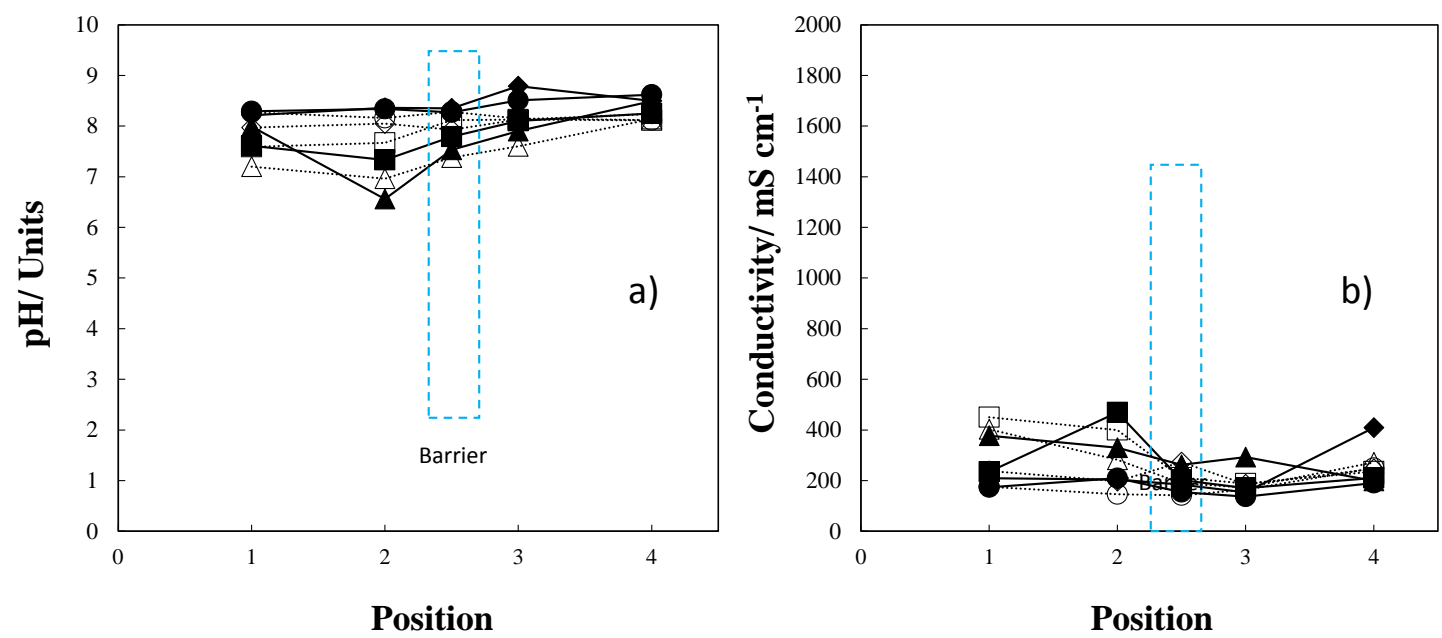

Figure 3. (a) $\mathrm{pH}$ map and (b) conductivity map of the soil after the remediation test for atrazine (full symbols) and oxyfluorfen (empty symbols) remediation. Upper right position $(\bullet, \circ)$, upper left position $(\mathbf{\square}, \square)$, bottom right position $(\diamond, \diamond)$ and bottom left position $(\boldsymbol{\Lambda}, \Delta)$ of the soil after the remediation test.

Figure 4 shows the transient changes of the fluxes and the moisture map at the end of the tests. The electroosmotic flowrates (fluid added to the electrode acting as the anode) increase over the tests to a value in the range of 0.04 to $0.05 \mathrm{~cm}^{3} \mathrm{~cm}^{-2} \mathrm{~d}^{-1}$. Moreover, the water evaporation fluxes are maintained approximately constant at a value close to 0.01 $\mathrm{cm}^{3} \mathrm{~cm}^{-2} \mathrm{~d}^{-1}$. According to part $\mathrm{b}$, the electro-osmotic fluxes help to maintain the moisture in the soil at values over $30 \%$ (initial value set) despite the evaporation because there is no moisture profile in the anode-cathode direction and the axial dispersion is low. Again, the reproducibility between both tests is a clear indicator of the robustness of the methodology used to evaluate the REKAB process at the bench scale. 

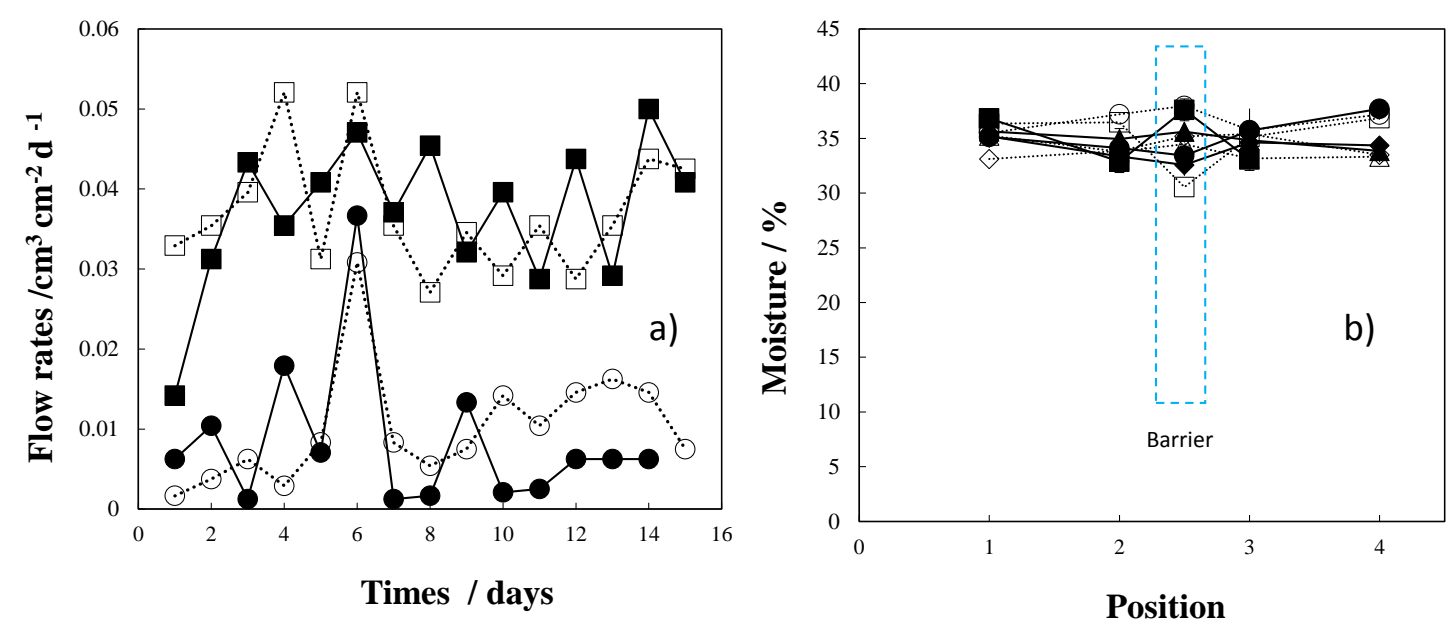

Figure 4. Time course of the electroosmotic flux $(\mathbf{\square}, \square)$ and evaporation flux $(\bullet, \circ)$ monitored during the remediation process. Moisture map of the soil following the remediation test. Upper right position $(\bullet, \circ)$, upper left position $(\boldsymbol{\square}, \square)$, bottom right position $(\diamond, \diamond)$ and bottom left position $(\boldsymbol{\Delta}, \Delta)$ of the soil after the remediation test. Atrazine (full symbols) and oxyfluorfen (empty symbols).

To obtain more information about the performance of the REKAB process in the removal of low-solubility pollutants, Table 1 compares the main changes observed during the REKAB tests with those obtained in a previous study in which the removal of atrazine and oxyfluorfen using EKSF was evaluated (Vieira dos Santos et al., 2016) with similar operating parameters. Comparison of the $\mathrm{pH}$ in the steady-state values obtained in the REKAB and in the EKSF indicates that there are important differences between both EK configurations, with more extreme $\mathrm{pH}$ values in the case of the EKSF technology with both herbicides. A clear influence of the acidic and alkaline fronts completely moving the soil matrix is observed in the $\mathrm{pH}$. A decrease in the $\mathrm{pH}$ values is generally observed in the sections near the anode, and a significant increase is observed in the sections near the cathode. However, as previously explained, with the application of REKAB, these more extreme $\mathrm{pH}$ values are not achieved, and in this case, it can be inferred that the polarity reversal contributes to efficient performance. Note that the combination of EK with PRB 
is occasionally considered for eliminating the obstruction of the PRB system caused by mineral precipitation or obstruction of active sites (Cameselle and Reddy, 2013).

Regarding conductivity, during the two tests, significant changes were observed in the electrolyte contained in the wells. These changes are more important in the EKSF without polarity reversal than in the REKAB process, and they are consistent with the fluctuations observed in the soil in the EKSF, with higher axial dispersions in the proximity of the electrode wells. This behaviour can clearly be attributed to the transport of ionic species and the fluctuations in the $\mathrm{pH}$ values. Comparing the values obtained in REKAB with those obtained in EKSF, the conductivity value is higher in the process studied in this work. This higher value can be explained because in contrast to EKSF, the periodic reversal of the polarity prevents the washing up of ions contained in the soil. This is also observed by comparing the conductivity of the electrolytes contained in the wells, which is significantly higher in the case of EKSF. However, in this case, not only the transport of ions but also the more extreme changes in the $\mathrm{pH}$ should be taken into consideration.

Table 1. Comparison of steady-state $\mathrm{pH}$, conductivity and moisture obtained after applying 15-day long remediation test (EKSF [29] or REKAB) to soil spiked with atrazine (ATZ) and oxyfluorfen (OXY).

\begin{tabular}{|c|c|c|c|c|}
\hline & $\begin{array}{l}\text { EKSF } \\
\text { (ATZ) }\end{array}$ & $\begin{array}{c}\text { EKSF } \\
(\mathrm{OXY})\end{array}$ & $\begin{array}{c}\text { REKAB } \\
\text { (ATZ) }\end{array}$ & $\begin{array}{c}\text { REKAB } \\
\text { (OXY) }\end{array}$ \\
\hline $\mathbf{J}\left(\mathbf{A ~ ~ m ^ { - 2 } )}\right.$ & 2.87 & 3.41 & 4.71 & 4.59 \\
\hline Moisture (\%) & 25.55 & 32.82 & 33.99 & 34.99 \\
\hline pH anode/cathode & $1.98 / 14.55$ & $2.04 / 14.01$ & $8.59 / 10.00$ & $7.95 / 11.00$ \\
\hline Conductivity $\left(\mu \mathrm{S} \mathrm{cm}^{-1}\right)$ anode/cathode & $6417 / 18942$ & $5326 / 9389$ & $1154 / 915$ & $569 / 769$ \\
\hline Post-mortem pH & 7.63 & 7.74 & 8.08 & 7.91 \\
\hline Post-mortem Conductivity $\left(\mu \mathrm{S} \mathrm{cm}^{-1}\right)$ & 157.90 & 183.90 & 238.5 & 241.04 \\
\hline Flow rate added $\left(\mathrm{cm}^{3} \mathrm{~h}^{-1}\right)$ & 3.6 & 7.3 & 4.7 & 4.5 \\
\hline Flow rate collected $\mathrm{EK}\left(\mathrm{cm}^{3} \mathbf{h}^{-1}\right)$ & 3.2 & 4.5 & 4.1 & 4.2 \\
\hline
\end{tabular}


Regarding the moisture of the soil, no important differences were observed between the two processes, despite the large changes in the values of the flow rates, in which the difference (associated with evaporation) is higher for the REKAB approach.

Figure 5 shows the concentration of herbicides measured in both electrode wells during the tests and the 3-D map of the pollutant distribution at the end of the tests. Regarding the pollutant distribution, part a shows the concentration map of atrazine and oxyfluorfen in the tests. As shown, after 15 days of treatment, a decrease in the concentration of pesticides remaining in the soil is registered until the concentration is lower than $5 \mathrm{mg}$ per kg of soil, and both pollutants, atrazine and oxyfluorfen, were efficiently removed, achieving approximately $90 \%$ removal during the treatment of soil. The significantly high concentrations of atrazine and oxyfluorfen in the central region of the soil after the treatment can be attributed to the presence of GAC-PRB. Regarding the herbicide collected in the electrode wells (part b), note that the daily change in the electrode polarity allows both wells to act as either the anode or the cathode depending on the day. The final concentrations of atrazine and oxyfluorfen collected in the electrode wells are very low, which means that polarity reversal is not a very good option for efficient EK transport. This observation was also noted with the conductivity. However, it was not the main removal mechanism sought with the REKAB process; rather, this process utilized the adsorption of the pollutant in the activated carbon bed placed in the soil column. 

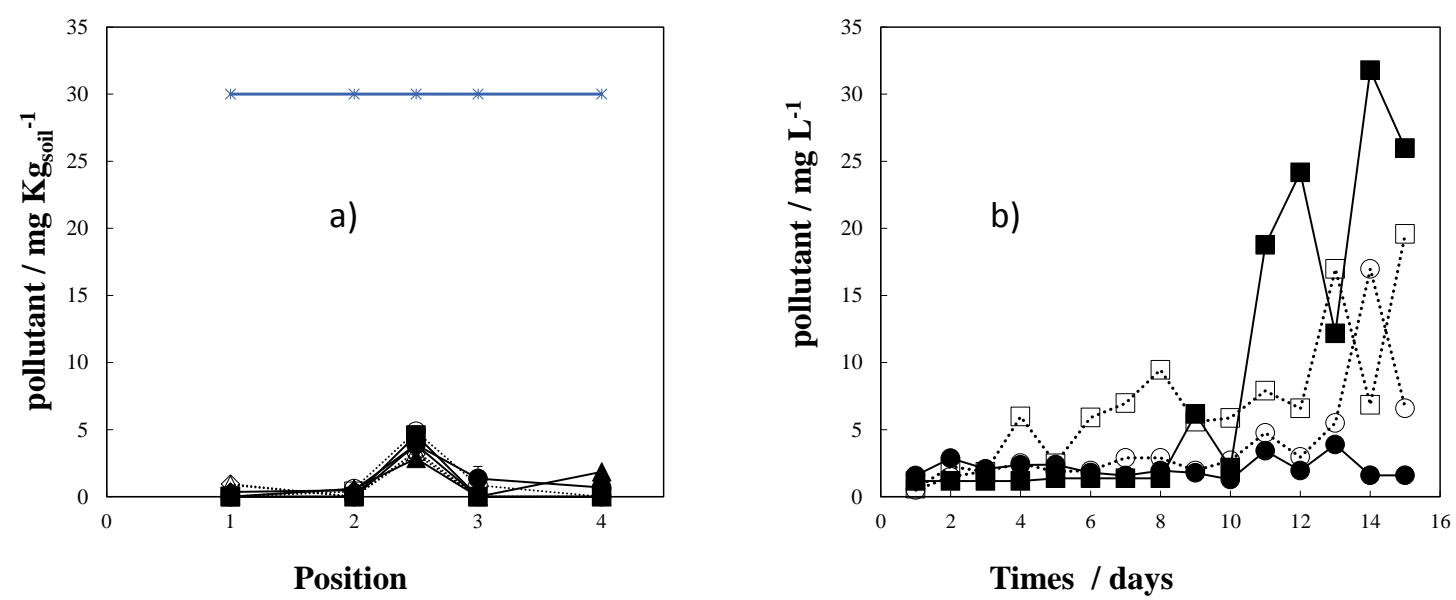

Figure 5. (a) Concentration map of the soil after the remediation test for both atrazine (full symbols) and oxyfluorfen (empty symbols). Upper right position $(\bullet, \circ)$, upper left position $(\boldsymbol{\square}, \square)$, bottom right position $(\diamond, \diamond)$ and bottom left position $(\boldsymbol{\Lambda}, \triangle)$ of the soil after the remediation test. (*) initial concentration of pollutants. (b) Changes in the concentrations of atrazine (full symbols) and oxyfluorfen (empty symbols) that arrive at the electrode wells during the remediation test. Concentration in the anodic chamber $(\square, \square)$, concentration in the cathodic chamber $(\bullet, \circ)$.

The different adsorption capabilities of GAC towards atrazine and oxyfluorfen can be easily understood by examining the adsorption isotherms (Figure 6), which were estimated for the concentration range of interest by mixing solutions containing $100 \mathrm{mg}$ $\mathrm{dm}^{-3}$ of herbicide and different amounts of activated carbon. As shown, the adsorption capacity of the activated carbon is not saturated for the concentration range tested, and the adsorption capacity of oxyfluorfen is higher than that of atrazine, which is consistent with the results obtained in the REKAB process. Likewise, it is confirmed that activated carbon is effective for the removal of both herbicides, despite their low solubility. 


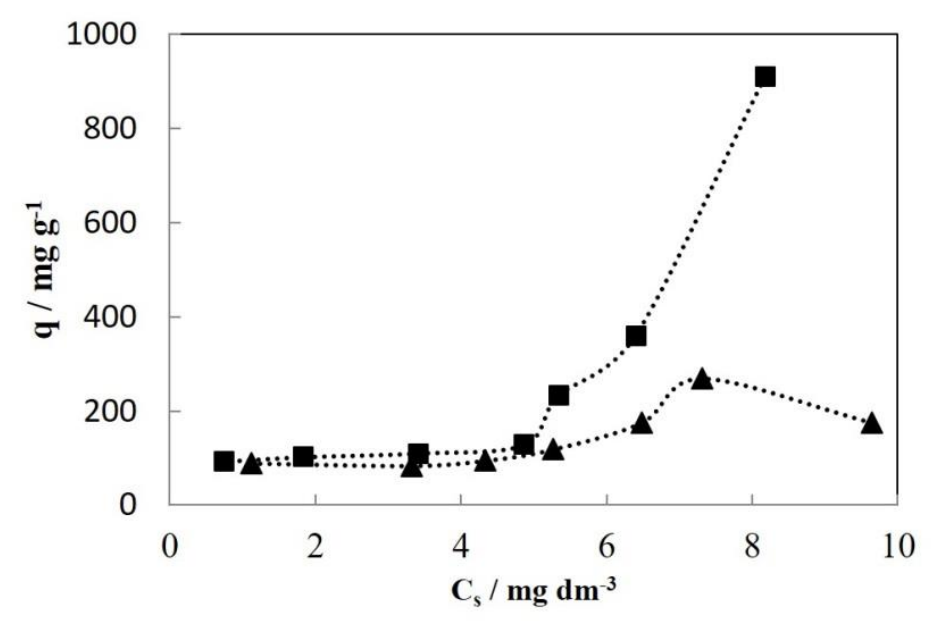

Figure 6. Adsorption isotherms of ( $\boldsymbol{\Delta})$ atrazine and ( $\boldsymbol{\square})$ oxyfluorfen onto the activated carbon used. Experimental conditions: batch tests using agitated vessels ( $0.25 \mathrm{~L})$ with 0.1 L solutions of $100 \mathrm{mg} \mathrm{L}^{-1}$ atrazine and oxyfluorfen and increasing amounts (2 to $100 \mathrm{mg}$ $\mathrm{L}^{-1}$ ) of activated carbon during $24 \mathrm{~h}$ until equilibrium.

Figure 7 compares the average concentration profile in the soil after 15 days of treatment in the removal of the two herbicides by REKAB and EKSF. Similarities between the behaviours for both pesticides were also observed during the application of the EKSF process, and it is very interesting to compare the profiles of pesticides in soil after the application of the two remediation technologies because it may help to understand the transport mechanism, and hence, it could be used to optimize the removal. In the case of the REKAB process, the herbicide concentration profiles after the tests are more similar, clearly indicating that a better removal of atrazine is achieved, which is in contrast to the better removal of oxyfluorfen observed in the case of EKSF. This behaviour can be explained by the more efficient adsorption indicated by the adsorption isotherms. 


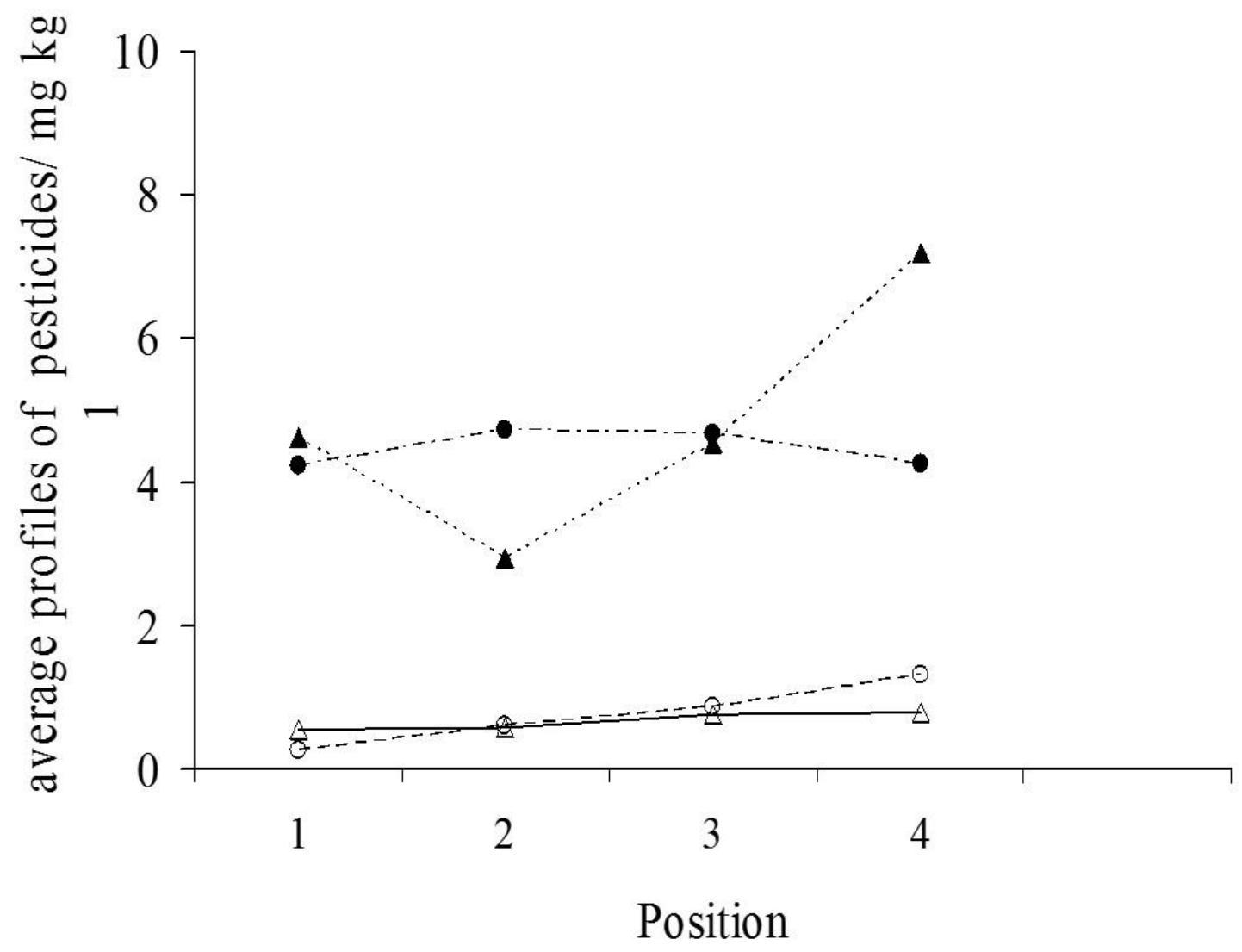

Figure 7. Average profiles of the pesticides at the end of tests. Atrazine $(\circ, \bullet)$ and Oxyfluorfen $(\Delta, \boldsymbol{\Delta})$. Reversible electrokinetic adsorption barrier (REKAB): Empty points; electrokinetic soil flushing (EKSF): full points.

In summary, the mechanisms for the removal of herbicides in both technologies are very different. The percentages of herbicides removed by the different mechanisms and the herbicides remaining in the soil after 15 days of treatment are shown in Figure 8. This figure compares the results for the removal of the herbicides in this work with those of a previous work focused on atrazine and oxyfluorfen using the same technology and experimental device (Vieira dos Santos et al., 2016). In the case of atrazine and oxyfluorfen, their removal is significantly favoured when these pollutants are mobilized by electromigration and electro-osmotic fluxes. 


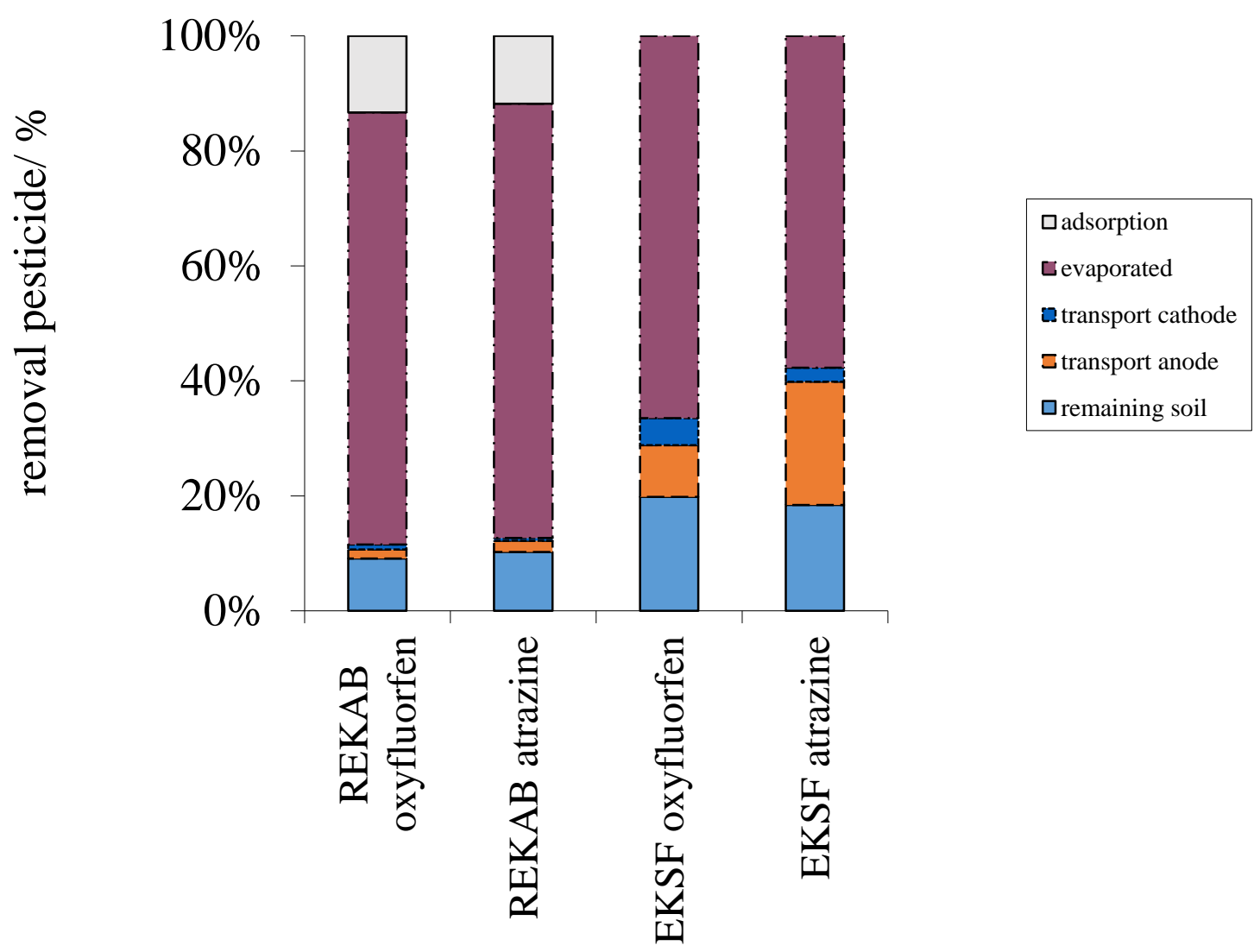

Figure 8. Average profiles of the herbicides at the end of tests.

Despite being similar herbicides, this figure highlights the importance of bench-scale studies for understanding the performance of EK soil remediation technologies. Even for two herbicides that are insoluble in water, the mass balance indicates that removal strongly depends on the adsorption and volatility properties. Even when the evaporation phenomenon appears to be important during the soil treatment, the evaporated fractions do not depend on the herbicide contained in the soil but rather only on the characteristics of the soil. Note that this type of phenomenon naturally occurs, and considering this phenomenon, innovative alternatives for soil remediation can be applied. These 
experiments are in progress, and their results will be reported in detail in a separate paper in the near future.

\section{Conclusions}

From this work, the following conclusions can be drawn:

- REKAB is an efficient technology for the removal of non-polar herbicides from soils.

- The combination of EKSF with adsorption-PRB technology in short periods (15 days) appears to be an innovative alternative to depollute soils.

- There are important differences between REKAB and EKSF. The adsorption of pesticide onto activated carbon prevents evaporation.

- Atrazine and oxyfluorfen are efficiently transported in the combined REKAB technology by electromigration and electro-osmotic processes.

- Polarity reversal has a positive effect on regulating the $\mathrm{pH}$ and on preventing the washing up of the salts contained in the soil.

\section{Acknowledgements}

The authors acknowledge financial support from the EU and Spanish Government through the MINECO Project CTM2013-45612-R. Financial support from the National Council for Scientific and Technological Development - Brazil (CNPq - 446846/2014-7) is gratefully acknowledged.

\section{References}


Cameselle, C., Reddy, K.R., 2013. Effects of periodic electric potential and electrolyte recirculation on electrochemical remediation of contaminant mixtures in clayey soils. Water Air Soil Poll. 224, 1-13.

Choi, J.-H., Kim, Y.-H., Choi, S.J., 2007. Reductive dechlorination and biodegradation of 2,4,6-trichlorophenol using sequential permeable reactive barriers: Laboratory studies. Chemosphere 67, 1551-1557.

Chung, H.I., Lee, M., 2007. A new method for remedial treatment of contaminated clayey soils by electrokinetics coupled with permeable reactive barriers. Electrochim. Acta 52, 3427-3431.

dos Santos, E.V., Saez, C., Martinez-Huitle, C.A., Canizares, P., Andres Rodrigo, M., 2016. Removal of oxyfluorfen from ex-situ soil washing fluids using electrolysis with diamond anodes. J. Environ. Manage. 171, 260-266.

Eason, C.T., Fairweather, A., Ogilvie, S., Blackie, H., Miller, A., 2013. A review of recent non-target toxicity testing of vertebrate pesticides: establishing generic guidelines. New Zeal. J. Zool. 40, 226-235.

Ferri, V., Ferro, S., Martinez-Huitle, C.A., De Battisti, A., 2009. Electrokinetic extraction of surfactants and heavy metals from sewage sludge. Electrochim. Acta 54, 2108-2118.

Frische, T., Bachmann, J., Frein, D., Juffernholz, T., Kehrer, A., Klein, A., Maack, G., Stock, F., Stolzenberg, H.C., Thierbach, C., Walter-Rohde, S., 2013. Identification, assessment and management of "endocrine disruptors" in wildlifein the EU substance legislation-Discussion paper from the German Federal Environment Agency (UBA). Toxicol. Lett. 223, 306-309. 
Garcia, Y., Ruiz, C., Mena, E., Villasenor, J., Canizares, P., Rodrigo, M.A., 2015. Removal of nitrates from spiked clay soils by coupling electrokinetic and permeable reactive barrier technologies. J. Chem. Technol. Biot. 90, 1719-1726.

Gomes, H.I., Dias-Ferreira, C., Ribeiro, A.B., 2012. Electrokinetic remediation of organochlorines in soil: Enhancement techniques and integration with other remediation technologies. Chemosphere 87, 1077-1090.

Grube, A., Donaldson, D., Kiely, T., Wu, L., 2007. Pesticides Industry Sales and Usage. 2006 and 2007 Market estimates. United States Environmental Protection Agency. Available at: www.epa.gov/opp00001/pestsales/07pestsales/market_estimates2007.pdf. Hayes, J.J., Marcus, D.L., 1997. Design of a permeable reactive barrier in situ remediation system, Vermont site. in: Evans, J.C. (Ed.). In Situ Remediation of the Geoenvironment. American Society of Civil Engineers, Minneapolis, MN, pp. 56-67. Huang, T., Li, D., Liu, K., Zhang, Y., 2015. Heavy metal removal from MSWI fly ash by electrokinetic remediation coupled with a permeable activated charcoal reactive barrier. Sci. Rep. 5, 15412.

Li, Z., Yuan, S., Wan, J., Long, H., Tong, M., 2011. A combination of electrokinetics and $\mathrm{Pd} / \mathrm{Fe} \mathrm{PRB}$ for the remediation of pentachlorophenol-contaminated soil. J. Contam. Hydrol. 124, 99-107.

Malpass, G.R.P., Miwa, D.W., Machado, S.A.S., Olivi, P., Motheo, A.J., 2006.

Oxidation of the pesticide atrazine at DSA (R) electrodes. J. Hazard. Mater. 137, 565572.

Mantzos, N., Karakitsou, A., Hela, D., Patakioutas, G., Leneti, E., Konstantinou, I., 2014. Persistence of oxyfluorfen in soil, runoff water, sediment and plants of a sunflower cultivation. Sci. Total Environ. 472, 767-777. 
Mena, E., Ruiz, C., Villasenor, J., Rodrigo, M.A., Canizares, P., 2015. Biological permeable reactive barriers coupled with electrokinetic soil flushing for the treatment of diesel-polluted clay soil. J. Hazard. Mater. 283, 131-139.

Mena, E., Villasenor, J., Canizares, P., Rodrigo, M.A., 2011. Influence of soil texture on the electrokinetic transport of diesel-degrading microorganisms. J. Environ. Sci. Health A 46, 914-919.

Mena, E., Villasenor, J., Canizares, P., Rodrigo, M.A., 2016a. Effect of electric field on the performance of soil electro-bioremediation with a periodic polarity reversal strategy. Chemosphere 146, 300-307.

Mena, E., Villasenor, J., Canizares, P., Rodrigo, M.A., 2016b. Influence of electric field on the remediation of polluted soil using a biobarrier assisted electro-bioremediation process. Electrochim. Acta 190, 294-304.

Oturan, N., Brillas, E., Oturan, M.A., 2012. Unprecedented total mineralization of atrazine and cyanuric acid by anodic oxidation and electro-Fenton with a boron-doped diamond anode. Environ. Chem. Letters 10, 165-170.

Palmer, P.L., 2001. Permeable Treatment Barriers. In Situ Treatment Technology. Lewis Publishers, Boca Raton, pp. 459-482.

Pazos, M., Rosales, E., Alcantara, T., Gomez, J., Sanroman, M.A., 2010.

Decontamination of soils containing PAHs by electroremediation: a review. J. Hazard. Mater. 177, 1-11.

Ribeiro, A.B., Rodriguez-Maroto, J.M., Mateus, E.P., Gomes, H., 2005. Removal of organic contaminants from soils by an electrokinetic process: the case of atrazine. Experimental and modeling. Chemosphere 59, 1229-1239. Rodrigo, M.A., Oturan, N., Oturan, M.A., 2014. Electrochemically assisted remediation of pesticides in soils and water: a review. Chem. Rev. 114, 8720-8745. 
Ruiz, C., Mena, E., Canizares, P., Villasenor, J., Rodrigo, M.A., 2014. Removal of 2,4,6-trichlorophenol from spiked clay soils by electrokinetic soil flushing assisted with granular activated carbon permeable reactive barrier. Ind. Eng. Chem. Res. 53, 840-846. Ryberg, K.R., Gilliom, R.J., 2015. Trends in pesticide concentrations and use for major rivers of the United States. Sci. Total Environ. 538, 431-444.

Santos, E.V.D., Sáez, C., Martínez-Huitle, C.A., Cañizares, P., Rodrigo, M.A., 2015. The role of particle size on the conductive diamond electrochemical oxidation of soilwashing effluent polluted with atrazine. Electrochem. Commun. 55, 26-29.

Scherer, M.M., Richter, S., Valentine, R.L., Alvarez, P.J.J., 2000. Chemistry and microbiology of permeable reactive barriers for in situ groundwater clean up. Cr. Rev. Microbiol. 26, 221-264.

Vieira dos Santos, E., Souza, F., Saez, C., Cañizares, P., Lanza, M.R.V., MartinezHuitle, C.A., Rodrigo, M.A., 2016. Application of electrokinetic soil flushing to four herbicides: A comparison. Chemosphere 153, 205-211.

Wan, J., Li, Z., Lu, X., Yuan, S., 2010. Remediation of a hexachlorobenzenecontaminated soil by surfactant-enhanced electrokinetics coupled with microscale $\mathrm{Pd} / \mathrm{Fe}$ PRB. J. Hazard. Mater. 184, 184-190.

Weng, C., 2009. Coupled electrokinetics-permeable reactive barriers. in: Reddy, K.R., Cameselle, C. (Eds.). Electrochemical Remediation Technologies for Polluted Soils, Sediments and Groundwater. John Wiley \& Sons, Inc. , Hoboken, New Jersey, pp. 483503. 